\title{
National Sustainable Consumption and Production Strategies in the EU
}

\author{
In the overall context of promoting sustainable \\ development, sustainable consumption and \\ production is an emerging field of targeted \\ policy making at alllevels of governance, world- \\ wide. In the European Union, governments \\ have chosen different ways to implement this \\ issue in the policy agenda. \\ By Jozsef Szlezak, Almut Reichel and \\ Hubert Reisinger
}

A $\mathrm{t}$ the Community level in the European Union (EU), the renewed EU Sustainable Development Strategy dating from June 2006 identifies Sustainable Consumption and Production (SCP) as one of seven key challenges to be tackled and, inter alia, makes a commitment for the development of an EU Action Plan on SCP.

As regards related policy making at the EU Member State level, above the implementation of related Community policies, SCP, in a broader sense, has already been addressed in several ways (1). Relevant activities may or may not be implemented in the name of SCP and include both top-down strategic approaches, i.e. the development of related overall and long-term strategic frameworks and initiatives and bottom-up instrumental approaches, i.e. the development of more focused or single-dimensional initiatives and related specific legislation as well as related institutional development and coordination.

\section{SCP as an emerging issue in national sustainable development strategies}

During recent years, as part of national strategic policy portfolios aimed at putting sustainable development into practice, SCP is being addressed in an increasing number of cases by dedicated national frameworks of programmes or action plans and/or integrated into the national sustainable development strategy (NSDS) as a key component. Figure 1 provides an overview of the most important SCP initiatives at the global and EU levels and also indicates examples of national SCP strategies in the EU.

The study National Sustainable Consumption and Production (SCP) Strategies in the EU - a comparative review of selected cases, the most important findings of which are summarised in this article, is one of the first attempts to provide an overview of examples of national strategies that address SCP per se in the EU (ETC/RWM-EEA 2007). The study was conducted by the European Topic Centre on Resource and Waste Management on behalf of and in cooperation with the European Environment Agency and served as background paper for the conference "Time for action - towards sustainable consumption and production in Europe" held from 27 to 29 September 2007 in Ljubljana, Slovenia (2).

During the period of information collection for the study, up to the end of August 2007, almost a dozen examples of dedicated SCP strategies or NSDSs integrating SCP as a key component were identified. In addition to the already existing strategies, several other examples where a relevant strategy had been under preparation were identified (3).

In terms of starting points, foci of action, instruments and targeted stakeholders these identified examples represent a very wide range of approaches. For the purpose of the comparative review, the following country cases were selected (4):

- The SCP perspective in the national sustainable development strategy of Austria, "Building our Future - a sustainable future for Austria” (2002) and its annual work programmes;

- The "Framework of Programmes on Sustainable Consumption and Production" (2005) in the Czech Republic;

【 "Getting More and Better from Less", the Finnish National Programme to Promote Sustainable Consumption and Production (2005);

- SCP as one of the identified key challenges in the national sustainable development strategy of France, "Acting in the European Dynamic" (2006);

- The UK Government programmes on sustainable consumption and production: "Changing Patterns - UK government framework for SCP” (2003) and Chapter 3 "One Planet Economy - Sustainable Consumption and Production", in "Securing the Future” (2005), the UK national sustainable development strategy (see also Bob Ryder's article in this issue). In the following, the most important findings of the comparative review are summarised.

\section{Priority implementation areas}

Overall, major new initiatives have been included in the strategies in all reviewed cases. Priority implementation areas defined in the strategies represent a very broad range. Nevertheless, some common main implementation areas, as well as the preferred tools and instruments of promoting SCP could be identified as follows (5). 
Figure 1: Overview of major overall SCP initiatives at the global and EU levels and examples of national SCP strategies in the EU

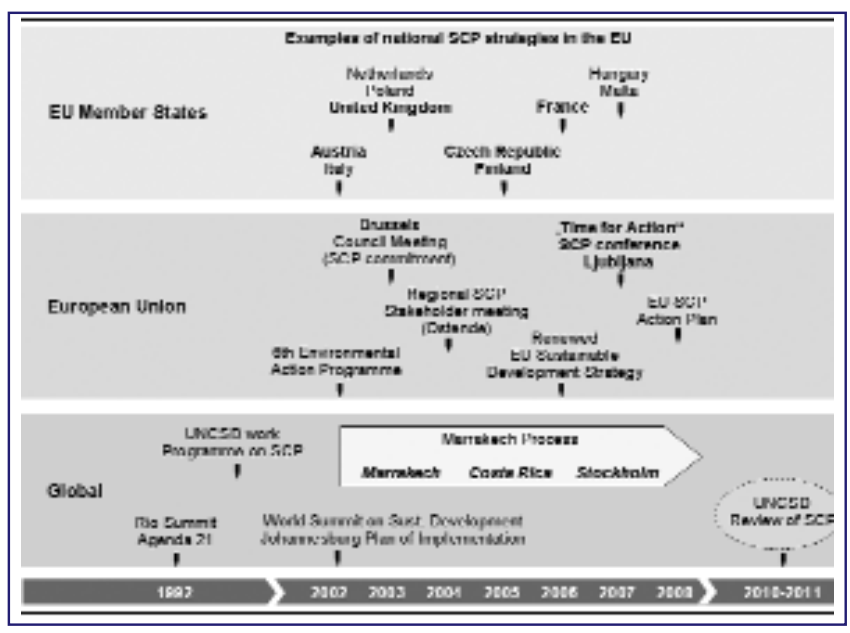

Source: ETC/RWM-EEA 2007

The most broadly and uniformly shared overall implementation area in the strategies is the improvement of eco-efficiency. For the most part, however, the context of planned efficiency improvements is the domestic economy and not the global supply chains with focus on production processes in contrast to entire production-consumption systems.

Commitment for setting the example in the public sector is in the forefront of each reviewed strategies and related ambitions usually go beyond Green Public Procurement.

Most common examples of planned action beyond Green $\mathrm{Pu}$ blic Procurement include the setting of mainly energy efficiency targets in the operation of public services and the consideration of social aspects in procurement processes.

A key role is assigned to market interventions in the promotion of SCP in all reviewed cases. The necessity of correcting externalities or market failures is broadly and uniformly recognised by the strategies. The most uniformly addressed overall implementation area in this respect is ecological tax reform or the increased use of environmental taxes.

Voluntary agreements also play an important role in a number of cases. For instance, the Austrian strategy makes commitment for the establishment of a nationwide voluntary sustainability reporting system for enterprises by the year 2010. In the Czech Republic, agreements which overall goal is to increase the availability of environmentally sound goods and improve their promotion are planned to be forged with retailers. There are only some sporadic examples of planned normative regulation.

\section{Private consumption patterns}

As regards consumption patterns in the private sphere, concrete planned measures and provisions included in the strategies largely focus on education, sensitisation for responsibility and the provision of information. In general, only few activities go beyond these issues or take a more holistic approach. One of the promising exemptions in this respect is the UK's so-called policy intervention diamond or the 4Es model of behavioural change, which suggest a coherent policy approach realising the principles of Enable, Engage, Encourage and Exemplify. Research aimed at understanding the dynamics of consumption decisions is also a broadly shared field of related planned action.

Further implementation areas according to seemingly common principles and goals are the promotion of a wide spectrum of SCP-related research and innovation, and, in a good number of cases, also product policy and the furthering of the environmental technologies sector.

Last but not least, intentions aimed at the institutionalisation of SCP are also an integral part of the strategies in most cases. The most typical forms of new institutions include the outsourcing of the implementation of specific initiatives to newly established government-funded bodies. For example, in the UK the Business Resource Efficiency and Waste Programme was set up for the period from 2005 to 2008 to enable business reducing the amount of waste they send to landfill. The Finnish SCP Programme had made a commitment for the establishment of a Material Efficiency Centre to support policies aimed at the improvement of eco-efficiency, which started its operation in 2007. The establishment of various coordination structures within government for the implementation of the strategy is also common, e.g. in France an inter-ministerial working group on the use of economic instruments is in operation and the implementation of the SCP Framework of Programmes is being monitored by the Working Group on SCP of the Government Council on Sustainable Development in the Czech Republic.

\section{Adressing of key consumption areas}

All countries associate food and drink consumption with SCP directly. The overwhelming focus under this broader category, however, is put on agriculture, that is on the production stage in the life-cycle. The life-cycle stage of distribution and retail is addressed only sporadically and consumption of meat products or food wastes in particular is not addressed directly in the strategies.

The production-consumption category of housing, as defined in related research (see e.g. Tukker et al. 2006), is not necessarily a differentiated category in the dedicated SCP strategies or associated directly with SCP in the national sustainable development strategies (NSDSs). As regards the construction phase of the life-cycle, the focus of the strategies is on the management of minerals, thermal insulation, voluntary standards for resource efficiency and in some cases construction-related waste management and the reuse of used goods and building components. As regards energy consumption and the use phase of buildings, related plans and measures, especially in the NSDSs, are rather included under the subject themes climate change and energy.

All strategies have a strong component on transport. Related action, similarly to the case of housing, however, is not necessarily a differentiated category in the stand alone SCP strategies 
or associated directly with SCP in the NSDSs. Personal mobility and the use of cars, which have been prioritised for action by related research, are broadly in the focus of strategies. Another common area is the provision of public transport services. The addressing of non-motorised mobility is also on the agenda in many of the strategies.

\section{Targets and indicators}

Quantitative targets for SCP were defined in the strategies very sporadically only. An exception to this is the Finnish SCP Programme, which has formulated several recommendations in this respect.

Despite this fact there seem to be SCP-related targets set in the countries, but they are included in the sectoral or thematic strategies. Based on these examples the most broadly and uniformly used SCP-related national targets are related to improvements in energy efficiency, the share of renewable energy in final consumption, the share of organic farming in total arable land and various types of targets in the transport sector, e.g. the split of modality.

As regards indicators, only France and the UK defined dedicated SCP sets of indicators, both within their larger set of sustainable development indicators. The Czech Republic defined potential clusters of SCP indicators. Austria and Finland at the time being monitor the implementation of SCP by their general set of sustainable development indicators.

\section{Some particular SCP considerations}

The main focus of the reviewed strategies lies on the ecological aspects of consumption and production. As regards interaction between the elements of sustainability, environmental, economic and social aspects, action representing win-win situation for the environment and the economy can widely be found in the strategies. Regarding social aspects, apart from a few exceptions, considerations do not go beyond the employment potential of planned action. The particular social drivers, e.g. demographic trends, of contemporary consumption patterns seem not to be amongst the main issues from the SCP perspective.

The strategies dominantly focus on domestic issues. In most of the cases they also contain an international dimension, where some important elements are covered, such as liberalisation of trade or promotion of the SCP concept in the international policy-making process. At the same time planned action taking the perspective of the global economy, burden shifting and the global use of resources is only very sporadic. Exceptions to this are several examples to promote the consumption of locally produced food.

The overall approach of the strategies seems to combine consistent planning using the building blocks of SCP like labelling, Green Public Procurement and education, with some more holistic considerations, according to the systems approach, for example fostering structural changes and new modes of satis- fying societal needs. As regards holistic considerations, the most broadly shared type of action in this respect is related to overall ecological tax reform or system of ecological taxation. Fostering structural change in agriculture and to a lesser extent in the transport sector is also a broadly shared category of ambitions.

\section{References}

ETC/RWM-EEA (European Topic Centre on Resource and Waste Management ( European Environment Agency): National Sustainable Consumption and Production (SCP) Strategies in the EU - a comparative review of selected cases. In: EEA: Time for action - towards sustainable consumption and production in Europe. Annex 2 of the EEA Technical Report No 1/2008. Internet: http://reports.eea.europa.eu/technical_report_2008_1/en

Tukker et al.: Environmental Impact of Products (EIPRO). Analysis of the life cycle environmental impacts related to the final consumption of the EU-25. Seville 2006.

\section{Annotations}

(1) Beyond traditional environmental policy, it also includes more recent product and/or consumer-oriented environmental policies as well, for example the compulsory labelling of household appliances, cars and buildings.

(2) The study, together with the other documents of the conference is available at: http://reports.eea.europa.eu/technical_report_2008_1/en

(3) For an updated list of national SCP strategies in place please visit the “UNEP Clearinghouse for National SCP Programmes at http://www.unep.fr/scp/nap/clearinghouse. It should also be noted here that there are various ways towards the operationalisation of SCP at the national level. Some countries have taken approaches which could rather be characterised as bottom-up or instrumental, for instance with a large number of individual pieces of SCP-related policies already in place, but no overall SCP strategy.

(4) Main selection criteria included the high level of political approval of the strategy, representation of a good spectrum of concrete actions planned in the strategy and representation of a wide geographical range of countries. (5) Findings of the study are presented in a decreasing level of uniformity in terms of the particular objectives and planned ways to achieve them per identified common priority areas, for instance at the top of the list is the priority implementation area which is addressed the most uniformly in the strategies.
I AUTHORS + CONTACT

Jozsef Szlezak is project manager and leader of the Sustainable Consumption and Production Topic Area at the Regional Environmental Center for Central and Eastern Europe (REC), Hungary. E-Mail: JSzlezak@rec.org

Almut Reichel is project manager at the European Environment Agency, Sustainable Consumption and Production and Waste Group.

Dr. Hubert Reisinger is a senior expert at the Federal Environment Agency (Umweltbundesamt GmbH), Austria. 
(c) 20I0 Authors; licensee IÖW and oekom verlag. This is an article distributed under the terms of the Creative Commons Attribution Non-Commercial No Derivates License (http://creativecommons.org/licenses/by-nc-nd/3.o/), which permits unrestricted use, distribution, and reproduction in any medium, provided the original work is properly cited. 